\title{
Physical Trauma and Its Consequences in Rural and Semi-Urban Regions of Low and Middle Income Countries
}

\author{
Haleluya Imanueli Moshi \\ Additional information is available at the end of the chapter
}

http://dx.doi.org/10.5772/intechopen.79545

\begin{abstract}
Trauma is a common occurrence in the rural and semi-urban regions of the low- and middleincome countries (LMICs) due to existence of risky infrastructure, socioeconomic, and cultural environments. Causes of trauma in these regions range from the commonest road traffic accidents, falls, burns, and assaults to the scarcely reported range of farmyard accidents. A majority of persons who survive trauma in these areas are evacuated from the incident scene and transported to the health facilities by laypersons by using any available vehicles. This state of handling potentially exposes trauma survivors to secondary injuries, worsening the disability and heightening risk to prehospital death. The cost managing persons with trauma is overwhelmingly high for rural areas of LMICs. Most governments of LMICs are not prepared to cater for individual traumatic incidents; so, if a permanent disability is a final outcome, the injured person and the immediate family have to bear the whole rehabilitation cost. In most cases, these rehabilitation costs are either unaffordable or unavailable to the family leading to provision of inappropriate assistive functional and mobility devices. Broader consequences include the inability to engage in income generating activities, while continuously draining the family economy, hence a poverty-disability vicious cycle.
\end{abstract}

Keywords: trauma, rural and semi-urban regions, low and middle income countries

\section{Introduction}

Though rarely reported, physical trauma remains one of the major causes of mortality and disability in the rural and semi-urban regions of the low and middle income countries (LIMCs). Unlike in the high income countries, where most occupational injuries happen in 
the formal sector and transportation, trauma in LMICs particularly rural regions occurs in informal occupations that are seldom monitored by occupational health laws and regulations. For example, a majority of the working class in the developing rural regions are informally self-employed in agricultural and entrepreneurship activities that are not governed by any occupational health and safety regulations. It can fairly be perceived that there are more factors for physical trauma in LMICs, as compared with developed regions, and so prevention is multifarious.

Causes of physical trauma in the rural and semi-urban regions are as diverse as the diversity in geographical, cultural, and socioeconomic features of these areas. For this reason, even within the same country, strategies to prevent and manage physical trauma ought to consider these variations. Furthermore, rural traumatic causes of physical injuries are significantly different from those dominating big cities even though they may be in the same country. For example, activities that involve climbing trees (from which one may fall) or working in the farmyard, hence a risk of being bitten by venomous insects or animals, are rare in big towns and cities of the high income countries but common in rural LMICs. Furthermore, individuals living in these regions continuously face danger of being attacked by either a domestic or wild animals which may charge and cause injuries. In one study in Ethiopia, both hospitalized and nonhospitalized persons who had suffered a dog bite were enrolled, and it was shown that more than 655 persons had suffered such injuries in a period of 1 year only [1]. Regardless of the population size, it is obvious that this is a high incidence rate and reflects poor legislation governing domestic animal keeping in most LMICs. Legislations for keeping domestic animal which are either ill-stipulated or lightly implemented add a risk of animal-related trauma to individuals living in LMICs. Furthermore, environmental and socioeconomic activities that add to the risk of trauma to the inhabitants of the rural areas are living in unsafe buildings, cooking in open fires, frequent head loading, working with sharp cutting objects, and working up or under trees. Head loading is the act of carrying heavy load on the head as means of transferring objects over a considerable distance. Head loading is a very common act among LMICs rural inhabitants in their crucial attempt to collect water, firewood, cattle feed, and crops to the homes or market place. In one of the centers for rehabilitation for persons who are paralyzed in Bangladesh, it was shown that for 3 years at least 84 persons had suffered cervical spinal cord injury as a result of falling while carrying heavy load on the head [2].

Trauma is costly in terms of evacuation, transportation, and management, and it is even worse when the individual has to remain permanently disabled. In the LMICs, this cost is normally borne by the individual and or immediate family as most countries have weak social support for a disabled person. Bearing in mind that rural and semi-urban regions of LMICs are residences for the poorest, this cost is unbearable in most cases. This unmet cost could explain the reported unavailability and unaffordability of transport services for trauma victims in these regions [3]. Delays and mismanagement of a traumatized person due to lack of appropriate equipment adds to the risk of secondary injury and death. Poorly managed and or rehabilitated victim of any physical trauma is at higher risk of health complications, dependency and in the worst case scenario, death. 
The author of this chapter is a senior physiotherapist and assistant lecturer at the Kilimanjaro Christian Medical Centre and University College in the North-East of Tanzania. Being born here, he has witnessed serious traumatic incidents resulting from very diverse risky activities and environment of rural and poverty-stricken regions within and around the Kilimanjaro region. While taking his Masters Studies for 2 years in Cape Town-South Africa, he had a chance to supervise undergraduate students in their clinical placement in Groote Schuur and Tygerberg hospitals in the Western Cape. He noted that in the Western Cape, the leading causes of trauma were far different from those dominating Tanzanian rural and townships. Furthermore, he wrote his Master's thesis (and now PhD) on occurrence and life after spinal cord injury in the rural settings of Tanzania. In both of his endeavors, he further noted that spinal cord injuries in rural settings of the LMICs result from various causes unique to these areas. In this chapter, he takes what he has learnt over the years as a clinician and a researcher and supports this with various studies from other settings with relatively similar characteristics. The literature search to support each subtopic of this chapter was carried out in PubMed, reference lists of various studies, and Google Scholar. Commonly used terms during the search were Trauma, injury, Rural, developing countries, low and middle income countries, and etiology.

\section{Causes of trauma in the rural and semi-urban regions of LMICs}

\subsection{Road traffic accidents}

Road traffic accidents are reported to be the leading cause of trauma and death globally due to the resulting fatal injuries, worse in most parts of LMICs. A novel cohort study carried out in sub-Saharan Africa reported that most of serious injuries in rural and semi-urban regions were due to road traffic accidents [4]. In rural areas of Bangladesh, for each 1 million people, 8890 gets injured of whom 60 dies annually due to road traffic accidents alone. It was also found out that of those who sustain RTAs as pedestrians, one-third died [5]. Still, like in many other trauma epidemiologic studies in LMICs, those who died before arriving to the hospital were lost to the count. For this reason, the reported figures do not reflect the true magnitude of the problem.

There are unique environmental, economic, and sociocultural factors that make RTAs prevalent in these regions of the LMICs. First, the number of vehicles does not match the available road space; hence, there is a congestion of pedestrians, cyclists, trees, and two motorcyclists. Most African rural and semi-urban regions have witnessed an influx of three- and twowheeled motorized vehicles as means of public transport, while the number of roads and structures remains more or less the same. Following the increase of motorized vehicles in limited road space in the LMICs, especially in the rural regions, the incidence of RTAs in the recent years has been escalated. A recent population-based study in one of the Tanzanian rural areas indicated that most road traffic injuries (RTIs) were due to motorcycle accidents, affecting males in their twenties [6]. Furthermore, most roads in LMICs have neither traffic 
lights nor warning signs and neither pedestrian walkways nor cyclist pathways. For this reason, motorized and nonmotorized vehicles and pedestrians share the same narrow road adding to the risk of accidents and trauma.

Most public busses in the rural and semi-urban regions are of poor quality due to aging or lack of maintenance service. As such vehicles are normally few when matched with the number of commuters, they are normally overloaded with passengers to alarming levels. It is also the scarcity of appropriate passenger vehicles that leads to the use of trucks and tractors which are not meant for passengers. Accidents involving such trucks and tractors normally causes massive trauma and deaths as the passengers are not secured at all. It is also not uncommon for drivers to be found without a driving license, driving drunk, or over-speeding and other human errors that contributes to risk of accident. Two studies carried out in LMICs reported that driving drunk, not applying protective measures, and over speeding were associated with increasing incidents of RTAs [7, 8]. The combination of human errors, vehicle defect, and risky infrastructure describes the reported high RTA incidents in the LMICs. Up to $74 \%$ of fatal RTAs in LMICs involve pedestrians [9]. Police road traffic accident data in Ghana showed that more than $40 \%$ of fatal RTA involved pedestrians, the majority being women [10]. Women being more affected as pedestrians in the LMICs can be explained by the fact that they are common venders and hawkers of food and items such as used clothes in rural and semi-urban LMICs. To carry out these activities, they have to walk or station themselves on the roadside to attract customers. On daily basis, many women share the insufficient road space with the four-, three-, and two-wheeled motorized and nonmotorized vehicles on their way to or from market, farm, or other places where they earn their living. In these situations, accommodate the current traffic, enforcement of the present laws, risk awareness, and behavior change campaigns by road users (particularly drivers of the motorized vehicles) may significantly reduce these such women are continuously exposed to risk of RTAs and trauma as pedestrians, while male subjects may be involved in RTAs as passengers or drivers. While it is costly and may take long to correct the infrastructure (increasing road space), immediate programs such as mass campaigns to promote safe use of roads by drivers and pedestrians could reduce RTAs.

There are other factors to road traffic accidents and trauma predominantly in the rural and semi-urban regions. Excessive alcohol consumption increases not only the odds of RTA but also assaults and falls which altogether accounts for incidents of physical trauma [4, 11]. Drunk-driving is one of the known major factors of RTAs, especially among youths in the rural and semi-urban regions of LMICs [12-14]. In one of the studies carried out in Tanzania, in which all injured drivers were tested for alcohol use it was found that up to $30 \%$ had exceeded the allowed levels [11]. This situation can be explained by the fact that there is quite a few number of road traffic police officers in these regions to monitor drivers behavior including alcohol consumption. On top of that, alcohol is easily accessible in these regions due to presence of alcohol outlets (bars) in almost every corner and people can drink at any time they wish. Some countries such as Tanzania have passed a law that restricts alcohol business during working hours with the aim of increasing productivity and crime reduction. This restriction can also reduce incidents of drunk-driving and minimize alcohol-related RTAs. Still, reducing the number of alcohol outlets and its frequent use in the rural and semi-urban LMICs is complex as it has to do with behavioral change and interferes with socioeconomic 
and cultural values of the people. For example, local wine is one of the business relied on by families in one of the sub-regions of Tanzania and Angola and also such brews has social and cultural values $[15,16]$. This means to reduce alcohol use in such regions requires extra effort in convincing people to change behavior and also encourage them to engage in alternative income generating activities.

There has been emergence of two- and three-wheeled motorized vehicles for public and private transport in many LMICs, particularly in rural and semi-urban regions $[9,17,18]$. These additional motorized vehicles have made the traffic denser and account for increase in the incidence of RTAs and injuries, especially in the lower limbs [10]. In Gambia for example, two-thirds of the RTA involved pedestrian, bicyclist, or motorcyclist [19]. Together with limited road space, there are several other safety issues to be addressed when motorcycles are used as means of public transport. Among such issues are adherence to safe use road by the cyclists. There are many cyclists in these regions who do not wear helmets and many of those who does, have inappropriate ones. For this reason, motorcycle accidents in these areas expose both the driver and passenger to head trauma. Furthermore, significant number of motorcyclists overloads the motorcycle by either carrying more than one passenger or other heavy loads beyond its ability $[7,17,18]$. It is therefore difficult for the driver to control the motorcycle especially in the case of emergency stop or changing direction, leading to accident and trauma. Most motorcycle drivers are young men in their teens and twenties, who are normally overconfident and feel proud to ride fast to catch up with "the next passenger" as soon as possible. In doing so, they add to the risk of accident and severity of the resulting trauma.

When these factors which precipitate the occurrence of RTAs in rural and semi-urban regions of LMICs are closely observed, it is noticeable that there are many which are modifiable. Some of these trauma precipitating factors can be addressed in the short-term and others in long-term plans. For example, while it may take long time to make better safer roads and a review on current driving regulations (where necessary), short-term efforts could be directed to correcting human errors such as speeding and drunk-driving. In order to reduce human errors that lead to accidents and trauma, the first step would be educating the public on safe road use and guiding them into perceiving of accident and trauma. People are more likely to respond if they perceive that they can sustain accidents and injuries and that this would affect their lives significantly. This is very much possible especially when it is done by engaging schools, spiritual institutions, and potential people who are trusted by the people such as political and faith leaders. In this way, road users (drivers, passengers, and pedestrians) will know their responsibilities and perceive the risk of trauma, injuries, and death linked to violation of road regulations. Hughes and colleagues presents a summary of models that have been used to reduce RTAs which can (selectively) be applicable in rural and semi-urban regions of LMICs as well [20]. Although rural and semi-urban regions of LMICs are understaffed with traffic police, civilians could be empowered to report on violated road regulations such as speeding, suspected drunk-driving, and overloading by calling or sending text messages to the nearby police station. In one study in Uganda, it was reported that almost a half of RTAs were precipitated by reckless driving [21]. This is possible because significant number of people in these regions have access to a cellular phone. 


\subsection{Falls}

Although road traffic accidents and falls are known as the leading cause for trauma in many parts of the world, there is still no single cause that dominates every region. Generally, falls are the second leading cause of trauma globally, but in some regions fall incidents surpass RTAs due to the predominating socioeconomic and cultural activities. For example, in a countrywide population-based study in Nepal, it was shown that falls were the leading cause of trauma followed by RTAs [22]. In most cases, falls from height in the rural and semiurban regions of LMICs are a result of socioeconomic and cultural activities that involve climbing trees. Socioeconomically there are several reasons why people in the rural and semi-urban regions of LMICs climb trees. First, climbing trees is necessary when one want to obtain fruits, which are either consumed by the family or sold to generate income. For example, falls from coconut trees and other types of fruit bearing trees have been reported in various rural regions of the LMICs $[23,24]$. Falling from palm trees is a common occurrence in the West African countries as they harvest palm heads and fruits for wine making [25]. In other incidents, people climb on prune trees to obtain dry branches or green leaves for firewood and animal feed, respectively [24]. Unlike the adults, children may climb trees in search of edible seeds and fruits or just for fun (e.g., pursuing small animals such as squirrels and demonstrating "climbing skills"). While up in the trees, one might lose a grip, an old branch may be broken, or attack by stinging insects or a snake may occur causing one to fall down.

Trees are not the only height from which trauma occurs in rural and semi-urban regions of LMICs. Other common heights from which people commonly fall are roof tops during construction or balconies, which are unsafe [26, 27]. These incidents are as a result of violation of occupational and residential safety guidelines either by ignorance or inability to afford safe construction materials. Depending on the height, injuries and fatalities are a common outcome of such fall incidents.

In these regions, there are significant number of events whereby falls happens as a result of slipping due to uneven road surface and wet or graveled rough road or pathways. These risky road surfaces coupled with absence of road lights and hardly any warning signs add to the risk of falls particularly during the night. For these reasons, falling while walking is a common occurrence especially among the elderly whose sight and protective balance are daunted. Although falls among elderly is globally common, those who live in the rural and semi-urban areas of LMICs have added risk of unfriendly road and pathways. The World Health Organization study on global aging and adult health involving LMICs reported more incidents of falls among elderly women than men and that rural dwellers had higher odds of fall as compared to those in townships and cities [28].

The worst case scenario is when individual falls with a heavy load on either the head or back. This may cause head, spine, and/or spinal cord injury especially on the cervical or lumbar region [24]. Various other consequences related to head loading including musculoskeletal pain disorders and minor injuries occurring in the spinal column, which may cause pain in the long run $[29,30]$. In these regions, head loading normally happens in the market places by persons 
who routinely carry heavy loads from the car to the market and vice versa. Also, common are women and children getting farm produce to the house or market, carrying water using containers of different shapes and sizes as well as getting animal feed or firewood to the home among other necessities $[29,31]$. The load carried on the head could be firewood for cooking, grasses, and leaves for animal feed or farm produce (cereals, banana, bags of fruit and vegetables) from farm to home or to the market $[29,30]$. Of recently, head loading has been referred to as a significant cause of disability in LMICs [30].

\subsection{Armed conflicts and wars}

Violence of any scale in which force and weapons are involved leads to enormous physical injuries and death. LMICs are disproportionally affected by armed conflicts due to rivalry between particular ethnic groups within or between countries. Although armed conflicts and wars are global, such incidents are predominantly more pronounced in the LMICs. Of recent years, armed conflicts are reported in various LMICs such as; Ethiopia, Libya, Nigeria, the Central African Republic, the Democratic Republic of Congo, Nigeria, Sudan, and South Sudan just to mention some. It is estimated that of all traumatic incidents resulting from armed conflicts, more than $50 \%$ are in Africa involving both the armed forces and civilians [32]. Following the Libya unrest of 2011 only, 1761 gunshot injuries were treated in one of the hospitals of whom more than $72 \%$ were directly associated with war and more than $27 \%$ involving stray bullets and civilian fighting [33]. In one of the military hospitals in Pakistan, 170 combats were identified in the period of 2 years in whom injury to blood vessels due to gunshot were reported. These combats required emergence repair of the injured blood vessels to serve their lives [34].

Although the most frequently reported war injuries are in the extremities, other body regions such as the head and spinal cord, thoracic, peritoneum, and pelvis sustain trauma are life threatening [35]. In order to save life and prevent disabilities, war injuries require timely medical and surgical response. However, in LMICs it is fewer victims of armed conflicts who get such a timely medical and surgical management, hence poorer outcome such as limb amputation and high mortality rate which could otherwise be reduced.

Consequences of war-related trauma are very extensive running from affecting the victims physically and mentally to stunting country's economy. In LMICs, trauma is an added burden to the already constrained economy. An injured victim of war who lives within environment of unrest and poverty faces a broader impact. First such person's ability to attain food, shelter, and clothing like everyone else has been shuttered. Second s/he needs medical, rehabilitative, and psychological services which are scarcely attainable. In most circumstances, the country's response to emergency situation is overwhelmed. In this situation, the injured victims may have to seek medical and surgical care from the nearby countries as refugees. In doing so, the consequences of war and unrest are spread to a wider geographical area. For example, between 2005 and 2007 only Iran received 130 injured victims of war from neighboring countries seeking medical and surgical services [36]. This means that the cost of managing war-related injuries in LMICs is incurred by a wider geographical region, draining even the economy of neighboring countries. 
Armed conflicts not only cause physical trauma, but also increases mortality rate. For example, while it is estimated that the crude mortality rate globally and in sub-Sahara region are 1.2 and 1.4, respectively, that of DR Congo during the unrest of 2006/2007 was 2.2 deaths in every thousand people. The mortality increase is not only on adult population for there are reports showing indicating an increase in death rate to post-neonatal in war born regions [37]. Furthermore, armed conflicts create poor living conditions and economic insufficiency. Although many people die as a result of direct trauma during the conflicts, many more are likely to die due to the resulting socioeconomic and environmental constraints such as disease outbreaks and hunger. Armed conflicts are so traumatic that they cannot be forgotten easily. For this reason, even those who survive the war, whether injured or not, still suffer depression.

\subsection{Other causes of trauma}

Other causes of trauma are less common when compared to road traffic accidents and falls but are of a relatively high incidence in the low and middle than in the high income countries. These other causes include; burns, assaults (either by human or animals), being fallen over by heavy load such as injuries due to a collapse of a wall, tree, or landslide. These causes make a big distinct epidemiological difference between LMICs and high income countries. Burns are among the most common cause of severe injuries, mortality, and disability which affects children than adults.

Assault incidents are frequently reported in these regions and in some studies in South Africa, Uganda, and Latin America are rated as the leading cause of trauma ahead of RTA and falls $[4,38,39]$. Assault incidents in these regions are associated with alcohol consumption, interpersonal, and ethnic conflicts [40,41]. Poverty as a result of high levels of unemployment among youths in these regions is also associated with violent crimes and attempt to earn a living by illegal means which includes forceful robbery. Incidents of alcohol consumption and violent behavior within lower and middle income countries can further be described. First, availability of local brews in so many alcohol outlets (bars) within the communities offers an opportunity people to access it easily. Local brews are cheap and are socially shared so that even those who cannot afford can still get a drink from a friend. Second, there are social events such as weddings, after burial and thanksgiving in the rural and semi-urban communities in which people can get local brews for free during such occasions. All these features increase accessibility to alcohol for the rural and semi-urban regions of LMICs. As a result, incidences of violence and assaults related to alcohol use increases simultaneously with the increase in traumatic incidents.

Venomous snakes, insects, and other animals that can bite and cause serious injuries are also common especially to rural areas of the LMICs. For example, in Bangladesh, rural areas snake bite had incidence of about 624/100,000 person years, the majority of who works in the farms [42]. In one study from India, most deaths from envenomation were due to scorpion stings and affected mostly the children in rural regions [43]. The incidents of snake bites are so common, and the World Health Organization has issued a guideline for management of such injuries [44]. Despite the issuing of the guideline by the WHO, the challenge that remains is making it accessible to the rural dwellers of the LMICs. Even when the guideline is accessed, read, and understood by the people, they may need to be enabled to attain the tools and equipment to respond to such incidents accordingly. 


\section{Common causes of trauma to children in the LMICs}

Children in rural LMICs incurs trauma frequently from various causes. Although children are also affected by RTAs and falls common causes of trauma in this group for rural and semi-urban regions is burns. Most of the burn injuries to children in these regions happens in the kitchen during cooking but may occur in other activities [45-47]. The use of open fires for cooking in areas is unsafe to children and elderly and ignorance on fire dangers are some of the contributing factors to burn accidents. In Uganda, it was found that burn is the leading cause of injury to children and in one hospital in Iran up to $47 \%$ of the burn cases were children less than 16 years of age [48]. Elsewhere in Bangladesh, a population-based study indicated that to every 100,000 children, 528 sustain burn injury of whom two may die while others recover with substantial impairments [45]. However, some studies reported that youth sustain burn injuries even more than children do. For example, in Nepal, it was found that young persons at the age between 24 and 25 had higher incidents of burn injuries than children [46]. A situational analysis of acute burn management in 32 low- and middle income countries indicated that most of the health facilities particularly in the rural and semi-urban regions were not equipped for burn management [49]. This being the case, it is reasonable to expect children who sustain burn injuries in these regions to have higher risk of disability and mortality as compared to those in higher income countries, where healthcare is more prepared for such incidents.

Apart from burn injuries, children in the rural and semi-urban regions of LMICs are faced by risks of other forms of physical trauma just like adults. As most of the rural areas of LMICs are characterized by trees and scarce play grounds, children not only tend to climb trees as part of their plays but also in search of edible seeds and fruits. In Bangladesh and India falling from height is one of the leading causes of trauma to children predominantly males dwelling in the rural and semi-urban regions $[50,51]$. There are also accounts of children falling from poorly constructed balconies and windows of which the majority dies and the remaining suffering serious injuries with potential for a long-term disability [27]. In India it was reported that fall from height is the second cause of pediatric head injury next to RTAs [51-53]. Incidents of RTAs involving children and teenagers in LMICs are markedly high as compared to the high income countries [54]. This increased risk of being involved in RTAs can be explained by the fact that a majority of children and teenagers walks to school (pedestrians) or plays near roads where they are exposed to accident and other forms of road-related trauma. Crosswalks are few and where available, they are either not used by children due to ignorance or abused by the drivers or motorized vehicle. This problem could be reduced significantly if community members could volunteer in one accord to guide children in safely using the roads especially when going or coming from school. There is a saying in Kiswaili that "Mtoto wa mwenzio ni mtoto wako" meaning that your fellow's child is yours. If such a saying is used in this setting, it means every person will view the child on the road as his or hers, hence ensuring safety to every child.

It is common in these regions for children to join their parents in different socioeconomic and cultural activities such as feeding cattle and farm works in what can be regarded as "learning by doing." While assisting or performing these tasks by themselves, children frequently sustains physical trauma due to mismatch between the forces demanded by the task against 
their physical abilities. Furthermore, children may not perceive risks of falling and getting injured as adults do. These two facts may account for injuries sustained by children when working in the rural and semi-urban regions. A study from one of the rural areas of Nigeria reports that most children with ocular injuries sustained were injured while working in the farms or playing [55]. Furthermore, children are comparatively vulnerable to physical trauma during dangerous incidents that may happen in their residences. These dangerous incidents are such as a fall of a poorly constructed house, throwing of wreckages during strong winds, earthquakes, and heavy rains. Youths and young adults may manage to escape in such disastrous incidents, while a majority of children fail to do so hence sustaining physical trauma.

\section{Emergency services following trauma in the rural and semi-urban regions of the LMICs}

There is evidence that prehospital mortality can be reduced significantly by good emergency services following trauma which includes first aid and timely and safe transport to health facility [56]. In most LMICs reporting and life supporting systems to sustain the injured person and transportation to health facility are unreliable and indeterminate [3,57]. It is common for injured person in rural and semi-urban regions of LMICs to be handled haphazardly at the trauma scene and transported by laypersons to the health facility by any means possible. For example, in Zambia, a report showed that the majority of injured persons were transported to the hospital by private cars and it was less than $6 \%$ who were transported by ambulance after trauma [3]. In this way, there is a significant delay to get to a health facility and increased risk of secondary trauma and mortality. In most cases, an injured person is given what is regarded as "first aid" by laypersons who happened to be at the incident scene. While such effort to save life is with good intention, this could be of more harm than helpful especially when handling delicate cases such as severe visceral, chest, head, and spinal cord injuries. Noting this danger, some programs to train laypersons on assisting and transporting a trauma victim have yielded convincing results $[3,58]$.

While training civilians to help trauma victims seems to be the best option for countries where emergency services are immature or unavailable, there are still issues on the package of training and the population coverage. Trauma varies in type, severity, and complexity of management. Even with good training on basic life support to laypersons, it would be difficult to major life threatening injuries such as those involving head, pelvis, and multiple viscera. Another limitation is that such training of skills requires practical session which may not be that feasible to a big group of learners (population). Furthermore, basic tools and equipment necessary for evacuation, first aid, and transportation of injured person are normally not readily available to complement the acquired knowledge and skills. For this reason, there ought to be a political will to facilitate not only the acquisition of basic knowledge and skills to manage a trauma victim, but also sustainable provision of basic tools for such a task. One useful approach would be inclusion of such information and skills training in school curriculums simultaneously with provision of practical tools. This will to create awareness and orient children with skills for safe handling of an injured person at basic level. This also means that 
elementary school teachers and school environment will be equipped to deliver such education and skills. There are other opportunities in LMICs to train laypersons on this regard. For example, women cell groups, village community banking (VICOBA) meetings, and faith based gatherings such as churches and mosques. However, as civilian services are hardly standardized and rarely sustainable, LMIC governments should be encouraged to plan for paramedic services which will ensure that a seriously injured person is handled by a well trained personnel from incident scene.

\section{Consequences of trauma to rural and semi-urban regions of the LMICs}

Rural and semi-urban regions of the LMICs are predominantly inhabited by the poorest of the world population. In general terms, poverty instigates risky activities and poor environmental and occupational safety standards leading to trauma and the resulting disability is also associated to future poverty, hence a vicious cycle [59]. For this reason, any financial-demanding preventive, curative, or rehabilitative strategies against trauma and its consequences are severely limited. Although there is scarcity of reports on trauma-related health costs from LMICs, it is generally apprehended that such cost is unbearably high to this population $[59,60]$. Consequently, persons who sustains trauma in these regions either dies (before or immediately on arriving to the health facility) due to a lack of emergency and life support services or remains with irreversible disability. It is "lucky" for a seriously injured person from these regions to survive without any residual significant impairment. Inadequacy in evacuation, transportation, and timely management of trauma casualties are factors prehospital mortality, secondary injury, and disability which could otherwise have been avoided.

The cost associated with trauma-related disability in these regions is rarely researched, but it is an irrefutable fact that they are common and costly in these regions. Reporting in the bulletin of the World Health Organization, Gosselin and colleagues refers to injuries as a neglected burden in LMICs [60]. It is indeed forgotten as very few projects on trauma are carried out and or published from these regions. When matched against country-specific gross domestic product (GDP) trauma in the rural and semi-urban regions of the LMICs are astronomically costly. It is estimated that most countries in the LMICs spend between 1.1 and 2.9 of their Gross Domestic Product (GDP) to trauma due to RTAs alone [61, 62]. In Thailand, it was estimated that for 10 years, more than 5 billion dollars had been used due to RTAs-related trauma [63]. Trauma also induces a significant straining on the already resource-constrained health system individual and immediate family.

In these regions, there are hardly any published estimates of social costs due to trauma including those resulting from other causes such as falls, burn, and assaults. However, it is known that most developing countries lack basic social security system from which a person who incurs trauma can be supported to attain healthcare and rehabilitation services accordingly. This means that the whole treatment cost for someone with significant trauma is left to the individual and immediate family. It follows that if the injured person and immediate family 
are financially unstable there is a failure in affording necessary health and rehabilitation services. Even in countries where there may be exemption (after thorough social assessment) for persons who cannot afford hospital bill, the challenge remains on getting to and being admitted in such hospital in the first place. A recent study in Uganda reported that among the difficulties faced by individuals with trauma included inability to attain and afford transport to the hospital and pay for treatments. For this reason, they had to rely on social support from close relatives and friends [64].

Injuries resulting from traumatic forces may recover fully or leave the individual with either a temporary or permanent disability. Of these three possible outcomes, permanent disability is most costly to the individual and immediate family. This cost is due to the fact that persons with permanent disability require health-sustaining and rehabilitation services including assistive devices throughout life. Such devices are necessary for them to carry out activities of daily living, pursue a career, and engage in their communities. Essential assistive devices range from relatively affordable hand sprints (for activities of daily living) to more expensive wheelchairs which are a prerequisite for mobility and function. Majority of individuals with severely lower limbs impairments such as total paralysis are left with no other means of mobility except a wheelchair. Unfortunately, essential assistive devices are either unavailable or unaffordable in most rural and semi-urban inhabitants of the LMICs. Again, the burden affording assistive devices is also left to the person and/or immediate family who (in most cases) cannot cover the entailed cost [65]. As a result, a majority of disabled persons lack assistive devices or obtain inappropriate one as a donation. Lacking appropriate functional and mobility device leaves the disabled person in a state of dependence in various aspects. Dependence that results from lack of assistive devices adds to the perceived severity of disability [66]. This disability culminates poverty to the person and affects the whole family particularly the dependents.

\section{Conclusions}

Rural and semi-urban regions of LMICs are predominantly characterized by numerous cultural, socioeconomic, and environmental factors for physical trauma. Existence of such factors sets the inhabitants of these regions at higher risk of physical trauma than those living in the city and high income countries. RTAs are the leading cause of trauma in most of these regions as a result of overcrowding of four-, three-, and two-wheeled motorized and nonmotorized vehicles and pedestrians in limited road spaces. Added factors for RTAs in these regions are: common drunk-driving and speeding behavior and infrastructure deficiencies such as lack of road lights and signs. Fall from trees and other falls (including falling with a load on the head) are other significant causes of physical trauma in these regions. Uniquely, these falls are precipitated crucial and necessary socioeconomic and cultural activities of the people making it complex to reduce incidents of tree climbing. Children sustain not only burn injuries, but are also common victims of fall from trees.

The majority of persons who sustain trauma in these regions are haphazardly handled and transported to health facility by laypersons hence increasing risk of secondary trauma and prehospital death. Evacuation, transport to health facility, management, and future rehabilitation 
of permanent disability is the end outcome is very costly. Such cost is incurred by the injured individual with his or her immediate family. There are also continuous disability-related health and rehabilitation cost such as function and mobility assistive devices which are also left to families to meet. Being a poor setting, most disabled persons and their families struggle to meet the entailed cost. As a result, a majority of disabled persons in these regions lack appropriate devices to enable their functioning. As a result, they end up being almost always dependent on others socioeconomically and in activities of daily living. This state lowers the quality of life and increases poverty levels to persons with disability and their families.

\section{Author details}

Haleluya Imanueli Moshi ${ }^{1,2 *}$

*Address all correspondence to: luluwayesu@gmail.com

1 Kilimanjaro Christian Medical Center, Faculty of Rehabilitation Medicine - Physiotherapy, Moshi, Tanzania

2 Faculty of Medicine, Department of Community Medicine and Rehabilitation Physiotherapy, Umea University, Sweden

\section{References}

[1] Beyene TJ et al. Determinants of health seeking behaviour following rabies exposure in Ethiopia. Zoonoses and Public Health. 2018;65(4):443-453

[2] Hoque MF et al. Cervical spinal cord injury due to fall while carrying heavy load on head: A problem in Bangladesh. Spinal Cord. 2012;50(4):275-277

[3] Mowafi $\mathrm{H}$ et al. Analysis of prehospital transport use for trauma patients in Lusaka, Zambia. World Journal of Surgery. 2016;40(12):2868-2874

[4] Diamond MB et al. Prevalence and risk factor for injury in sub-Saharan Africa: A multicountry study. Injury Prevention. 2018;24(4):272-278

[5] Ul Baset MK et al. Pattern of road traffic injuries in rural Bangladesh: Burden estimates and risk factors. International Journal of Environmental Research and Public Health. 2017;14(11):1-28

[6] Zimmerman $\mathrm{K}$ et al. Road traffic injury on rural roads in Tanzania: Measuring the effectiveness of a road safety program. Traffic Injury Prevention. 2015;16(5):456-460

[7] Boniface R et al. Factors associated with road traffic injuries in Tanzania. The Pan African Medical Journal. 2016;23:46

[8] Reardon JM et al. The epidemiology and hotspots of road traffic injuries in Moshi, Tanzania: An observational study. Injury. 2017;48(7):1363-1370 
[9] Naci H, Chisholm D, Baker TD. Distribution of road traffic deaths by road user group: A global comparison. Injury Prevention. 2009;15(1):55-59

[10] Damsere-Derry J, Palk G, King M. Road accident fatality risks for "vulnerable" versus "protected" road users in northern Ghana. Traffic Injury Prevention. 2017;18(7):736-743

[11] Staton CA et al. The impact of alcohol among injury patients in Moshi, Tanzania: A nested case-crossover study. BMC Public Health. 2018;18(1):275

[12] Bachani AM et al. Knowledge, attitudes, and practices around drinking and driving in Cambodia: 2010-2012. Public Health. 2017;144S:S32-S38

[13] Aigbokhaode AQ, Isah EC, Isara AR. Health seeking behaviour among caregivers of under-five children in Edo State, Nigeria. South East Asia Journal of Public Health. 2015:1-10

[14] Peltzer K, Pengpid S. Drinking and driving among university students in 22 low, middle income and emerging economy countries. Iranian Journal of Public Health. 2015;44(10):1330-1338

[15] Haule MJ. Bamboo wine business and rural livelihood of Songea District, Tanzania. Tanzania Business Education Journal. 2015;1(1):1-25

[16] Monizi M et al. The Cultural and Socio-Economic Role of Raffia Palm Wine in Uíge Province, Angola. 2018. pp. 119-129

[17] Kamulegeya LH et al. The scourge of head injury among commercial motorcycle riders in Kampala: A preventable clinical and public health menace. African Health Sciences. 2015;15(3):1016-1022

[18] Matheka DM et al. Road traffic injuries in Kenya: A survey of commercial motorcycle drivers. The Pan African Medical Journal. 2015;21:17

[19] Sanyang E et al. Risk factors for road traffic injuries among different road users in the Gambia. Journal of Environmental and Public Health. 2017;2017:8612953

[20] Hughes BP et al. A review of models relevant to road safety. Accident; Analysis and Prevention. 2015;74:250-270

[21] PEBALO FP et al. Risk factors for road traffic accidents in Gulu Municipality, Uganda. East African Medical Journal. 2012;89(10):345-350

[22] Gupta S et al. Injury prevalence and causality in developing nations: Results from a countrywide population-based survey in Nepal. Surgery. 2015;157(5):843-849

[23] Mulford JS, Oberland H, Tovosia S. Coconut palm-related injuries in the Pacific Islands. ANZ Journal of Surgery. 2001;71:32-34

[24] Moshi $\mathrm{H}$ et al. Traumatic spinal cord injury in the north-east Tanzania-Describing incidence, etiology and clinical outcomes retrospectively. Global Health Action. 2017; 10(1):1355604 
[25] Mbuagbaw L, Noorduyn S. The palm wine trade: Occupational and health hazards. International Journal of Occupational and Environmental Medicine. 2012;3(4):157-164

[26] Bhatti JA et al. Fall-related injuries in a low-income setting: Results from a pilot injury surveillance system in Rawalpindi, Pakistan. Journal of Epidemiology and Global Health. 2015;5(3):283-290

[27] Grivna $\mathrm{M}$ et al. Pediatric falls from windows and balconies: Incidents and risk factors as reported by newspapers in the United Arab Emirates. World Journal of Emergency Surgery. 2017;12:45

[28] Stewart Williams J et al. Prevalence, risk factors and disability associated with fallrelated injury in older adults in low- and middle-incomecountries: Results from the WHO Study on Global Ageing and Adult Health (SAGE). BMC Medicine. 2015;13:147

[29] Porter G et al. Health impacts of pedestrian head-loading: a review of the evidence with particular reference to women and children in sub-Saharan Africa. Social Science \& Medicine. 2013;88:90-97

[30] Geere JA et al. Carrying water may be a major contributor to disability from musculoskeletal disorders in low income countries: A cross-sectional survey in South Africa, Ghana and Vietnam. Journal of Global Health. 2018;8(1):010406

[31] Sharma R, Singh R. Determination of safe carrying load limit for women carrying water. Journal of Ergonomics. 2012;02(02):1-12

[32] Bowman B et al. In: Bos ER et al., editors. Violence and Injuries, in Disease and Mortality in Sub-Saharan Africa. World Bank Publications: ProQuest Ebook Central; 2006. p. 414

[33] Mansor S, Bodalal Z. The impact of the method of gunshot injury: War injuries vs.stray bullets vs. civilian fighting. Journal of the College of Physicians and Surgeons-Pakistan. 2015;25(4):281-285

[34] Mishwani AH, Ghaffar A, Janjua S. Combat related vascular trauma. Journal of the College of Physicians and Surgeons-Pakistan. 2012;22(4):213-217

[35] Andersen RC et al. Extremity war injuries VIII: Sequelae of combat injuries. The Journal of the American Academy of Orthopaedic Surgeons. 2014;22:57-62

[36] Khoshmohabat $\mathrm{H}$ et al. The prevalence of trauma injuries from neighboring countries transferred to Iran. International Journal of Travel Medicine and Global Health. 2017;5(4):140-143

[37] Lindskog EE. The effect of war on infant mortality in the Democratic Republic of Congo. BMC Public Health. 2016;16(1):1059

[38] Joseph C et al. Incidence and aetiology of traumatic spinal cord injury in Cape Town, South Africa: A prospective, population-based study. Spinal Cord. 2015;53(9):692-696 
[39] Murray J, Cerqueira DR, Kahn T. Crime and violence in Brazil: Systematic review of time trends, prevalence rates and risk factors. Aggression and Violent Behavior. 2013;18(5):471-483

[40] Wolf A, Gray R, Fazel S. Violence as a public health problem: An ecological study of 169 countries. Social Science \& Medicine. 2014;104:220-227

[41] Pare PP, Felson R. Income inequality, poverty and crime across nations. The British Journal of Sociology. 2014;65(3):434-458

[42] Rahman R et al. Annual incidence of snake bite in Rural Bangladesh. PLoS Neglected Tropical Diseases. 2010;4(10):e860

[43] Anaya $\mathrm{AH}$. Incidence of deaths by poisoning animals in the endemic region during the twentieth century. Journal of Indian Academy of Forensic Medicine. 2013;35(2):156-159

[44] Warrell DA. In: WHO Library Cataloguing-in-Publication Data, editor. Guidelines for the Management of Snake-Bites. South-East Asia: World Health Organization, Regional Office for South-East Asia; 2010. pp. 1-162

[45] He S et al. Epidemiology of burns in Rural Bangladesh: An update. International Journal of Environmental Research and Public Health. 2017;14:4

[46] Gupta S et al. Burns in Nepal: A population based national assessment. Burns. 2015; 41(5):1126-1132

[47] Mirza Aghazadeh A et al. Lethal area 50 in patients with burn injuries in North West, Iran. Journal of Caring Sciences. 2018;7(1):53-58

[48] Batte A et al. Incidence, patterns and risk factors for injuries among Ugandan children. International Journal of Injury Control and Safety Promotion. 2018;25(2):207-211

[49] Joseph $\mathrm{K}$ et al. Assessment of acute burn management in 32 low- and middle-income countries. World Journal of Surgery. 2016;40(4):791-800

[50] Chowdhury SM et al. The horizon of unintentional injuries among children in lowincome setting: An overview from Bangladesh Health and Injury Survey. Journal of Environmental and Public Health. 2009;2009:435403

[51] Gururaj G. Injury prevention and care: An important public health agenda for health, survival and safety of children. Indian Journal of Pediatrics. 2013;80(Suppl. 1):S100-S108

[52] Chaitanya K et al. Traumatic brain injury in Indian children. Child's Nervous System: ChNS: Official Journal of the International Society for Pediatric Neurosurgery. 2018;34(6): 1119-1123

[53] Babu A et al. Are falls more common than road traffic accidents in pediatric trauma? Experience from a Level 1 trauma centre in New Delhi, India. Chinese Journal of Traumatology. 2016;19(2):75-78

[54] WHO. Global Status Report on Road Safety 2015. Italy: WHO; 2015. pp. 1-340 
[55] Okoye O, Ubesie A, Ogbonnaya C. Pediatric ocular injuries in a resource-deficient Rural Mission Eye Hospital in Southeastern Nigeria. Journal of Health Care for the Poor and Underserved. 2014;25(1):63-71

[56] Henry JA, Reingold AL. Prehospital trauma systems reduce mortality in developing countries: A systematic review and meta-analysis. Journal of Trauma and Acute Care Surgery. 2012;73(1):261-268

[57] Mulwafu W et al. Trauma care in Malawi: A call to action. Malawi Medical Journal. 2017;29(2):198

[58] Callese TE et al. Layperson trauma training in low- and middle-income countries: A review. The Journal of Surgical Research. 2014;190(1):104-110

[59] Banks LM, Kuper H, Polack S. Poverty and disability in low- and middle-income countries: A systematic review. PLoS One. 2017;12(12):e0189996

[60] Wesson HK et al. The cost of injury and trauma care in low- and middle-income countries: A review of economic evidence. Health Policy and Planning. 2014;29(6):795-808

[61] Wijnen W, Stipdonk H. Social costs of road crashes: An international analysis. Accident; Analysis and Prevention. 2016;94:97-106

[62] Hardcastle TC et al. The prehospital burden of disease due to trauma in KwaZulu-Natal: The need for Afrocentric trauma systems. World Journal of Surgery. 2013;37(7):1513-1525

[63] Chadbunchachai $W$ et al. Road traffic injuries in Thailand: Current situation. Journal of the Medical Association of Thailand. 2012;95(7):S274-S281

[64] Liang W, Chikritzhs T. Examining the relationship between heavy alcohol use and assaults: With adjustment for the effects of unmeasured confounders. BioMed Research International. 2015;2015:596179

[65] Thrush A, Hyder AA. The neglected burden of caregiving in low- and middle-income countries. Disability and Health Journal. 2014;7(3):262-272

[66] Hamid LN et al. Disability characteristics of community-based rehabilitation participants in Kayunga District, Uganda. Annals of Global Health. 2017;83(3-4):478-488 
